\title{
REDES SOCIAIS: UM ESTUDO DE CASO NO SETOR METAL MECÂNICO EM SÃO JOSÉ DOS PINHAIS - PR
}

\section{SOCIAL NETS: A STUDY OF CASE IN THE SECTOR MECHANICAL METAL IN SÃO JOSE DOS PINHAIS - PR}

\author{
Edinéia Aparecida Ivankio; ; Fernando Claudino²; June Alisson Westarb Cruz ${ }^{3}$; Natália Machado \\ Costa $^{4}$; Valdir Ribeiro da Silva ${ }^{5}$; Vilma Fatima de Campos Bergamasco ${ }^{6}$ \\ ${ }^{1}$ Pontifícia Universidade Católica do Paraná - PUCPR - São José dos Pinhais - Brasil \\ edineiaivankio@bol.com.br \\ ${ }^{2}$ Pontifícia Universidade Católica do Paraná - PUCPR - São José dos Pinhais - Brasil \\ fernando.claudino@hotmail.com \\ ${ }^{3}$ Pontifícia Universidade Católica do Paraná - PUCPR - São José dos Pinhais - Brasil \\ june.cruz@ymail.com \\ ${ }^{4}$ Pontifícia Universidade Católica do Paraná - PUCPR - São José dos Pinhais - Brasil \\ natalia tati2004@yahoo.com.br \\ ${ }^{5}$ Pontifícia Universidade Católica do Paraná - PUCPR - São José dos Pinhais - Brasil \\ valdir.silva@pr.senai.br \\ ${ }^{6}$ Pontifícia Universidade Católica do Paraná - PUCPR - São José dos Pinhais - Brasil \\ vilma@acospinhais.com.br
}

\begin{abstract}
Resumo
A globalização vem incentivando a necessidade de aumentar a competitividade, fazendo com que o estabelecimento de parcerias torne-se essencial. Um dos temas emergentes nos estudos organizacionais tem sido o conceito de redes organizacionais. Diante da grande concorrência enfrentada pelas organizações atualmente, as redes são ressaltadas como uma alternativa viável, representando uma resposta em torno de questões de competitividade, estratégia empresarial e estruturação organizacional. A presente pesquisa foi realizada numa rede de fornecedores $e$ clientes do setor metal-mecânico da região metropolitana de Curitiba - PR. O estudo objetivou compreender como este setor se relaciona e quais são seus principais atores, demonstrando sua evolução temporal no período (2008/2009). Como resultado, verificou-se a existência de um sistema de interação entre atores do canal de distribuição do setor metal-mecânico, denominados de fornecedores e clientes, em observância dos principais atores em estrutura relacional na rede.
\end{abstract}

Palavras-Chave: redes sociais e organizacionais, análise de redes, metal-mecânico.

\section{Introdução}

Em um mercado cada vez mais dinâmico e turbulento, a concorrência entre empresas industriais vem crescendo significativamente desde o inicio dos anos 90. Sendo o setor metal mecânico atualmente considerado competitivo a nível mundial, com um parque industrial relativamente moderno colocando a disposição produtos de qualidade compatível com as exigências 
do mercado e baixos custos de produção e sendo o Brasil, o país ocupante da 9 a posição no ranking da produção mundial, em 2008 de acordo com o IBS - Instituto Brasileiro de Siderurgia. O estudo buscou compreender como o setor metal-mecânico da região metropolitana de Curitiba - Paraná se relaciona numa configuração de redes e quais os principais atores. Portanto, se faz necessário entender a rede de relacionamento entre clientes e fornecedores deste setor, que trabalham com um produto de "commodities", que segundo Porter (1986) tem como estratégia genérica a liderança total em custos. Atualmente, as empresas se organizam por meio de redes sociais que, segundo Powell (1990) se apresenta como conjuntos de conexões entre pessoas e/ou organizações relacionados entre si, com estruturas abertas capazes de ampliar de forma ilimitada, integrando novos nós estabelecendo a comunicação dentro da rede e compartilhando os mesmos valores ou objetivos de desempenho.

Diante deste contexto, o presente estudo tem como objetivo geral identificar como o setor metal-mecânico da região metropolitana de Curitiba - Paraná se relaciona numa configuração de redes e quais os principais atores; por meio dos seguintes objetivos específicos: Identificar os principais atores da rede por meio do seu montante $(\mathrm{R} \$)$ comercializado (clientes e fornecedores); Identificar os principais atores relacionais do setor na região separados em fornecedores e clientes; Identificar a estrutura da rede de fornecedores e clientes nos períodos de 2008 e 2009; Identificar dinamicidade dos elos relacionais e montantes $(\mathrm{R} \$)$ comercializados na rede nos períodos de 2008 e 2009 separados em fornecedores e clientes.

Nesse sentido, o estudo se apresenta estruturado nos seguintes itens: introdução, base teórica, metodologia, apresentação e análise dos dados e considerações finais.

\section{Base teórica}

A presente base teórica é estruturada nos seguintes tópicos: Redes; Tipos de Redes; Aglomerados; Clusters; Redes Sociais e Arranjo Produtivo Local.

\subsection{Redes}

A perspectiva do estudo em redes apresenta-se cada vez mais emergente nas expectativas de mercado, diante do exposto sua origem apresenta-se na palavra em latim retis, que segundo Rodrigues (CRUZ, 2007) significa o entrelaçamento de fios com aberturas regulares que formam uma espécie de tecido. A partir desta abordagem, a palavra rede foi ganhando novos significados ao longo dos tempos, passando a ser empregada em diferentes aspectos. Reafirmando o conceito descrito, Castells (2002) trata rede como sendo um conjunto de nós ligados entre si, seguindo da base que o nó seria o ponto no qual uma curva se interliga. A partir daí, uma estrutura em redes 
significa que seus integrantes são ligados a todos os demais horizontalmente diretamente ou através daqueles que os cercam.

Em contraste ao que foi descrito acima, Burt (1992) conceitua redes levando em consideração seus benefícios quando esta passa a ser um canal de acesso a atores com recursos como poder, status, capital social ou outros específicos, sendo que esta estrutura de rede é utilizada para prever semelhanças ou comportamentos padronizados entre os envolvidos na rede.

De um modo mais amplo, o conceito de redes é um conjunto de relações ou laços entre atores, sendo que os atores podem ser tanto indivíduos ou organizações. O conteúdo do laço é o tipo de relação existente e a forma se refere à força e a intensidade da relação, e qualquer tipo de relação social pode ser definida como um laço (MARTES et al., 2008).

\subsubsection{Tipos de redes}

A fim de uma melhor compreensão do sistema de redes, faz-se necessário uma descrição mais aprofundada de sua tipologia, Andion (2003), ressalta a grande valia da identificação do tipo de rede apresentada, devendo demonstrar a origem dos laços de harmonia presentes. As relações existentes entre os agentes locais envolvidos precisam estar devidamente mapeadas e estes identificados para que sua descrição seja mais abrangente. Diante do exposto Casarotto e Pires (2001) relatam a existência dos seguintes tipos de redes: Rede de Empresas: compreendem um conjunto de empresas entrelaçadas por relacionamentos formais ou simplesmente negociais, podendo ou não ser desenvolvida em determinada região; Consórcio de Empresas: os atores da rede apresentam-se entrelaçados por laços formais de cooperação, normalmente circunscrita a uma região; Pólo ou Aglomerados: os participantes apresentam-se em uma concentração regional de empresas voltadas ao mesmo segmento de produtos; Cluster: pólo consolidado havendo forte interação entre as empresas. Comporta entidades de porte público e privado. É organizado e estruturado; Arranjo Produtivo Local: a região apresenta-se fortemente estruturada, contendo um ou mais clusters, com planejamento territorial com alta interação entre instituições publicas e privadas, tendo como principal objetivo assegurar a qualidade de vida; Redes Sociais: apresentam características semelhantes às demais, entre elas observam-se à conformidade em prol de um objetivo comum entre os atores, a descentralização na tomada de decisões, entre outras características abordadas a posteriori.

Sob mesmo foco, Cruz, Martins e Augusto (2008) a seguir, no quadro 01 descrevem as principais características dos principais tipos de redes a partir de uma adaptação da tipologia estabelecida por Lemos (2004). 
Quadro 01 - Características dos tipos de redes

\begin{tabular}{|c|c|c|c|c|}
\hline \multirow[b]{2}{*}{ Características } & \multicolumn{4}{|c|}{ Tipos de Redes } \\
\hline & Aglomerados & Cluster & $\begin{array}{c}\text { Arranjo produtivo } \\
\text { local }\end{array}$ & Redes Sociais \\
\hline $\begin{array}{l}\text { Tipos de atores } \\
\text { envolvidos }\end{array}$ & $\begin{array}{l}\text { Organizações } \\
\text { privadas e } \\
\text { públicas. }\end{array}$ & $\begin{array}{l}\text { Organizações } \\
\text { privadas e } \\
\text { públicas }\end{array}$ & $\begin{array}{l}\text { Organizações } \\
\text { privadas, públicas, } \\
\text { instituições de ensino, } \\
\text { organizações não- } \\
\text { governamentais, } \\
\text { associações, sindicatos } \\
\text { e comunidade em } \\
\text { geral. }\end{array}$ & $\begin{array}{l}\text { Organizações privadas, públicas, } \\
\text { instituições de ensino, } \\
\text { organizações não- } \\
\text { governamentais, associações, } \\
\text { sindicatos e comunidade em } \\
\text { geral. }\end{array}$ \\
\hline Forma dos atores & Organizações & Organizações & Organizações & Organizações e indivíduos. \\
\hline Tipologia & De mercado & $\begin{array}{l}\text { De mercado e de } \\
\text { comunicação }\end{array}$ & $\begin{array}{l}\text { De mercado, de } \\
\text { comunicação } \\
\text { e de apoio }\end{array}$ & De apoio \\
\hline $\begin{array}{l}\text { Modelo de } \\
\text { rede }\end{array}$ & $\begin{array}{l}\text { Vertical e } \\
\text { horizontal }\end{array}$ & $\begin{array}{l}\text { Vertical e } \\
\text { horizontal }\end{array}$ & Vertical e horizontal & Horizontal \\
\hline $\begin{array}{l}\text { Organizações em } \\
\text { uma determinada } \\
\text { área geográfica }\end{array}$ & Concentradas & Concentradas & Concentradas & Concentradas \\
\hline $\begin{array}{l}\text { Tipos de } \\
\text { organizações }\end{array}$ & Diversos setores & $\begin{array}{l}\text { Um setor ou } \\
\text { atividade }\end{array}$ & Um setor ou atividade & $\begin{array}{l}\text { Um ou mais setores ou } \\
\text { atividades }\end{array}$ \\
\hline $\begin{array}{l}\text { Nível das } \\
\text { estratégias }\end{array}$ & Organizacionais & Organizacionais & $\begin{array}{l}\text { Entre todos os agentes } \\
\text { locais }\end{array}$ & Entre todos os agentes locais \\
\hline Ações & Competitivas & $\begin{array}{l}\text { Competitivo- } \\
\text { cooperativo }\end{array}$ & $\begin{array}{l}\text { Competitivo- } \\
\text { cooperativo, }\end{array}$ & Cooperativas \\
\hline $\begin{array}{l}\text { Forma de } \\
\text { interação } \\
\text { predominante }\end{array}$ & Formal e informal & Formal & Formal & Informal \\
\hline $\begin{array}{l}\text { Fatores essenciais } \\
\text { de fortalecimento }\end{array}$ & $\begin{array}{l}\text { Proximidade } \\
\text { geográfica, } \\
\text { semelhança de } \\
\text { mercado e } \\
\text { competências } \\
\text { regionais. }\end{array}$ & $\begin{array}{l}\text { Proximidade } \\
\text { geográfica, } \\
\text { semelhança de } \\
\text { mercado, } \\
\text { competências } \\
\text { regionais e forte } \\
\text { concorrência. }\end{array}$ & $\begin{array}{l}\text { Proximidade } \\
\text { geográfica, } \\
\text { semelhança de } \\
\text { mercado, } \\
\text { competências } \\
\text { regionais, forte } \\
\text { concorrência e } \\
\text { cooperação social. }\end{array}$ & $\begin{array}{l}\text { Confiança, reputação } \\
\text { e cooperação. }\end{array}$ \\
\hline $\begin{array}{l}\text { Estabelecimento } \\
\text { de objetivos }\end{array}$ & Não existe & $\begin{array}{l}\text { Estabelece } \\
\text { objetivos comuns } \\
\text { entre parceiros }\end{array}$ & $\begin{array}{l}\text { Estabelece objetivos } \\
\text { comuns com todos os } \\
\text { agentes locais }\end{array}$ & $\begin{array}{l}\text { Estabelece objetivos comuns } \\
\text { com todos os agentes locais }\end{array}$ \\
\hline $\begin{array}{l}\text { Responsáveis } \\
\text { pelas ações }\end{array}$ & $\begin{array}{l}\text { Administradores e } \\
\text { gerentes da } \\
\text { empresa }\end{array}$ & $\begin{array}{l}\text { Administradores e } \\
\text { gerentes da } \\
\text { empresa }\end{array}$ & $\begin{array}{l}\text { Agentes articuladores } \\
\text { e agentes locais }\end{array}$ & $\begin{array}{l}\text { Agentes articuladores e agentes } \\
\text { locais }\end{array}$ \\
\hline Cadeia produtiva & Desvinculada & Integrada & Integrada & Integrada \\
\hline Benefícios & Econômicos & Econômicos & $\begin{array}{l}\text { Econômicos, sociais, } \\
\text { culturais e ambientais }\end{array}$ & $\begin{array}{l}\text { Econômicos, sociais, culturais e } \\
\text { ambientais }\end{array}$ \\
\hline $\begin{array}{l}\text { Tipo de emprego } \\
\text { estimulado }\end{array}$ & Formal & Formal & Formal e informal & Formal e informal \\
\hline
\end{tabular}

Fonte: Cruz (2008)

\subsubsection{Aglomerados}


De acordo com Porter (1999, p. 211) "aglomerado é um agrupamento geograficamente concentrado de empresas inter-relacionadas e instituições correlatas numa determinada área, vinculadas por elementos comuns e complementares". Os aglomerados constituem-se de empresas setoriais a jusante (pode ser distribuidores ou clientes), fornecedores, instituições governamentais e outras vinculadas por meio de elementos comuns ou complementares, numa abrangência que pode variar de uma única cidade ou estado até mesmo países vizinhos (PORTER, 1999).

Nesse contexto o objetivo de um aglomerado é se fortalecer como um todo por meio da soma de todas as forças e que essa união de alguma forma proporcione vantagens para os envolvidos (PORTER, 1999).

A percepção das fronteiras do aglomerado pode ser identificada nas relações verticais e horizontais, dos elos principais, cujas relações estão em constante evolução, devido à dinamicidade das relações dentro de um aglomerado (HUTT, et al., 2000). Porter (1999) descreve que a proximidade dos mercados, possibilita uma interação eficiente entre as empresas correlatas e seus fornecedores, fortalecendo os elos do aglomerado.

Segundo Amato Neto (2000), dentro do conceito de coletividade, embora a eficiência possa estar estabelecida e implementada nas relações de um aglomerado de empresas, os resultados podem ser diferentes, algumas empresas podem crescer, enquanto outras tendem a cair. Atuar de forma conjunta minimiza e possibilita a solução de diversos problemas comuns às organizações.

Porter (1999) conclui que os aglomerados representam uma maneira que complementa o entendimento de economia, promoção do desenvolvimento econômico e o estabelecimento de políticas governamentais, além de desempenharem um papel de suma importância na competição, gerando informações relevantes para as empresas, governo e outras instituições sistematizadas e relacionadas entre si.

\subsubsection{Cluster}

De maneira abrangente, pode-se entender cluster como sendo a concentração setorial e geográfica de empresas (AMATO NETO, 2000). O mesmo autor atenta para o fato da necessidade de identificação de uma série de características próprias dos clusters, independentemente de seu nicho de atuação, tipo de produto ou serviço, dentre elas a mais importante é a vantagem competitiva derivada das ações conjuntas. O autor salienta ainda que os clusters existem apenas quando ambos os aspectos setorial e geográfico estão concentrados, assim proporcionando um amplo escopo para a divisão de tarefas e especialização para a inovação, sendo estes elementos essenciais para a competição e mercados locais. Também é importante observar que mesmo sendo difícil caracterizar um cluster, pelo fato de que os sistemas produtivos nem sempre estão claramente separados nas categorias disperso ou aglomerado, havendo em alguns casos um mix dessas duas 
categorias, isso não altera o fato principal de que a aglomeração proporciona ganhos de eficiência coletiva que raramente seriam atingidos em produtores separados (AMATO NETO, 2000).

Quandt, Cruz e Lemos (2008, p.175) se aprofundam no tema e definem que “clusters são constituídos por empresas que se organizam em redes locais, e desenvolvem gradualmente processos de integração e mecanismos de cooperação, solidariedade e valorização do esforço coletivo". Ressaltam ainda que como resultado desses processos tem-se o desenvolvimento da competitividade sistêmica, ou seja, torna-se possível alcançar com mais facilidade objetivos do que com atuação isolada de uma empresa.

Segundo Amato Neto (2000), os clusters geralmente concentram apenas um ramo industrial, mas não necessariamente são formados por apenas um tipo de indústria, por isso são criticados quanto a sua vulnerabilidade, face os desafios impostos pela necessidade de constante atualização devido à inovações tecnológicas, fenômeno pouco apreciado nessas regiões.

De acordo com Porter (1998), os clusters afetam a competitividade tanto dentro quanto fora das fronteiras nacionais, representando uma maneira de desafiar conhecimento sobre como as empresas devem ser formadas, encarando a localização geográfica. Os clusters ainda promovem tanto a concorrência como a cooperação, é a competição entre os atores de um cluster que trazem o sucesso para ele e a cooperação está presente envolvendo empresa de setores afins e instituições locais.

Para Lins (2000) a aglomeração produtiva, não representa somente uma competitividade auto-sustentada, mas é condição favorável para criar sinergias e melhores articulações entre as várias economias externas ao aglomerado, favorecendo vínculos entre as organizações verticais, fornecedores e terceirizados e os membros de natureza horizontal, como compradores e traders, entre outros, por meio de atividades em conjunto, como: mecanismos de publicidade, aquisições de matérias primas e equipamentos comuns às empresas do aglomerado, envolvimento em conjunto das instituições públicas e privadas, fortalecendo estas relações.

Zaccarelli (2000, p. 198) destaca que um “cluster não é uma organização formalizada de empresas e diante disso, as empresas acabam agindo de forma integrada sem haverem planejado formalmente essa integração.”

\subsubsection{Redes Sociais}

Ainda que por vezes estudos sobre redes não tem sido algo muito aprofundado na literatura brasileira, muitos autores tem contribuído com conceitos, teorias e metodologias nesses últimos anos, tudo isso tem gerado uma vasta discussão acerca da emergência dos estudos sobre as redes sociais, um estudo que engloba várias áreas interdisciplinares. Seguindo o raciocínio dessas redes sociais, Cruz (2007) destaca as redes sociais como um fenômeno que possibilita a aproximação do 
Estado com a sociedade. Cruz Filho; Oliveira (2006) cita que uma rede exige dois fatores predominantes para seu fortalecimento, sendo eles confiança e cooperação, entre os indivíduos ou organizações. Tais redes podem ou não ter um viés para o lado econômico, pois provocam mudanças a partir da mobilização e organização dos atores sociais.

Com base nos estudos já realizados, Fischer e Spinosa (2008) destacam que o diferencial entre as redes sociais e os outros tipos de redes é a intencionalidade nos relacionamentos, os objetivos comuns focados em um determinado propósito, explicitados e compartilhados.

Segundo Shirky (2007), as redes sociais sempre estiveram paralelas às hierarquias das organizações, embora não sejam aparentes e nem de fácil detecção, são entendidas como ferramentas importantes às relações no mundo dos negócios. Estas redes, por vezes reais e outras virtuais, despertam o interesse dos investidores, empreendedores, colaboradores, dos fornecedores de matéria prima e equipamentos, entre outros.

Castells (2002) enfatiza que o fortalecimento das redes sociais se concentra nos elos sociais que aproximam os envolvidos, na facilidade de comunicação entre os agentes e no compartilhamento dos objetivos da rede com seus autores. Cruz Filho e Oliveira (2006) deixa claro que é essencial que grande parte dos relacionamentos dentro das redes sociais, seja definida por meio de relações informais, de modo que as relações formais e hierarquizadas não limitem o crescimento e amplitude das redes. De maneira geral, a atuação dos membros da rede social se dá forma ampla, por meio de relações informais, cuja abrangência pode atingir todos os setores da sociedade, com um objetivo único de atender as necessidades e expectativas sociais.

\subsubsection{Arranjo Produtivo Local (APL)}

Cassarotto; Pires (2001) enfatizam que o termo "solidariedade", é um diferencial determinante na conceituação entre cluster e APL (Arranjo Produtivo Local).

Para os mesmos, arranjo produtivo local são "redes cooperativas de negócios caracterizadas por uma concentração territorial, por especialização em torno de um produto básico e por ativa solidariedade entre vários atores, visando à qualidade de vida" (CASAROTTO; PIRES, 2001, p. 84).

Segundo Lemos (2004) o arranjo produtivo local, poderá ter sua origem a partir de cluster, desde que, estes tenham princípios em parcerias estratégicas, com ampliação em práticas sustentáveis e são construídos a partir das sinergias e alianças locais e que podem ter, em virtude do nível de atuação num determinado setor, conseguir maior abrangência em um nível regional, compreendendo atores, como: instituições acadêmicas de ensino e pesquisa, clientes, fornecedores, governos e instituições locais, entre outros. 
Lemos (2004) enfatiza que para evoluir de um aglomerado para arranjo produtivo local, a figura de um articulador que tem origem na região é um agente determinante, para mobilizar e promover sinergias para a cooperação social, em busca de um objetivo comum a todos.

\section{Metodologia da pesquisa}

O estudo é classificado como exploratório, tendo como estratégia de verificação o estudo de caso. A partir da Empresa Aços Pinhais-PR, foi possível por acessibilidade coletar os dados primários. Tal evento foi possível pelo fato de a empresa estar localizada na região e tem elevado grau de relacionamento entre os principais atores da rede. Por meio do Software ERP LU SSA (Programa ZENTHI versão 6.5.2.23 for Windows) desta empresa, foram coletados os dados primários e os dados seqüenciais por meio de pesquisa, com aplicação do questionário de indicação. O presente estudo tem caráter temporal, sendo utilizados como período de referência, os anos de 2008 e 2009. Observe a seguir as especificidades das técnicas de coleta, análise e etapas da pesquisa.

\subsection{Técnica de coleta de dados}

A metodologia de estudo é natureza exploratória, e foi adotada amostra não probabilística por conveniência, em função das limitações deste tipo de abordagem e do acesso às empresas. Foram escolhidos os seguintes parceiros da cadeia de suprimentos: fornecedores de produto/serviço e clientes. A coleta de dados ocorreu por meio de: pesquisa bibliográfica e questionário.

\subsection{Técnica de análise de dados}

A técnica de análise de dados busca verificar as relações existentes entre o objeto de estudo e outros elementos. O estudo foi analisado, utilizando como ferramenta de análise o software UCINET 6 for Windows, desenvolvido nos laboratórios Analytic Technologies, na University of Greenvich.

Segundo Souza (2004) esse sistema de análise busca verificar as relações dos dados coletados, identificando as propriedades oriundas da interação entre os atores, suas estruturas e forma de organização. Após elaborar a matriz de adjacência, faz-se a análise dos dados, sendo possível verificar, a dinamicidade da rede e suas modificações relacionais, num certo período. $\mathrm{O}$ conjunto de elos e nós são os elementos primários do estudo das redes sociais e as qualidades dos atores com elementos secundários, este conjunto a partir da metodologia dos grafos (grafy teory) compõe um grupo de atores.

O método de estudo, faz análise descritiva dos gráficos e matrizes quadradas ou retangulares, compreendidas como as sociomatrizes $(\mathrm{X})$. Por meio das matrizes é possível 
identificar as relações e se há um padrão na interação entre os atores, o que dificilmente poderia ser percebido em sociogramas, onde a relação é entre pontos e linhas.

Neste tipo de análise, quase sempre, a diagonal da matriz é desconsiderada, trata-se de uma decisão arbitrária, embora o tipo de relação defina a regra a ser adotada para análise. As linhas (g) no sistema de matrizes representam os elos enviados e as colunas (b ou j) representam os elos recebidos. As entradas e saídas, que representam os elos, são importantes fatores para determinar o grau de centralidade local e global e para identificar os subgrupos na rede.

\subsection{Etapas da pesquisa}

As etapas iniciais ocorreram por meio de pesquisas bibliográficas e posteriormente foram realizadas as etapas de coletas de dados primários: por meio das listas de fornecedores e clientes 2008 e 2009 (Software ERP LU SSA, Programa ZENTHI versão 6.5.2.23 for windows), partindo para as respectivas análises.

A seguir é apresentado o quadro 02 que define as etapas seqüenciais que serão adotadas no desenvolvimento da pesquisa.

Quadro 02 - Etapas da pesquisa

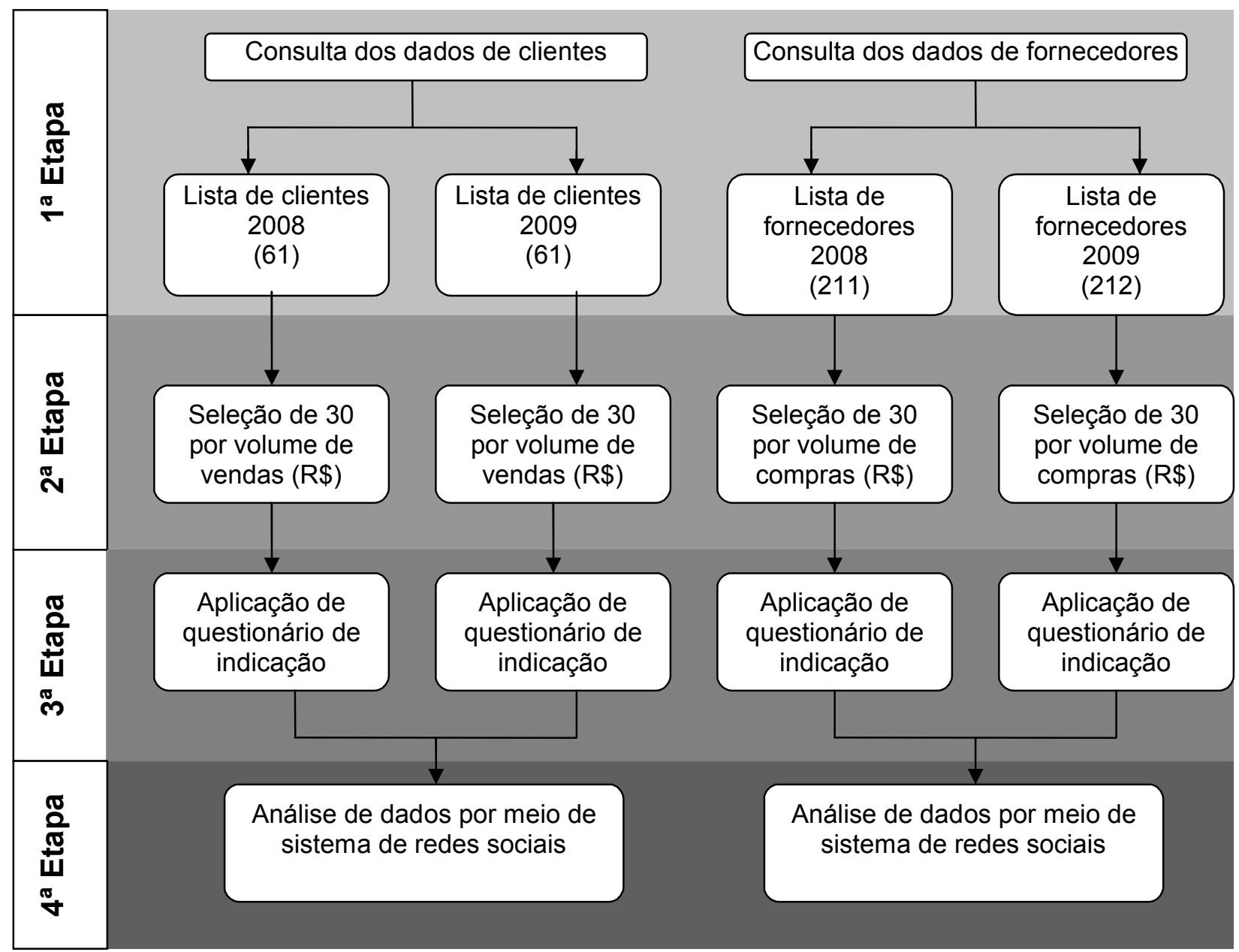

Fonte: Autoria própria (2010) 
As etapas foram desenvolvidas conforme descrição abaixo:

$1^{\text {a }}$ ETAPA: Foram coletadas as planilhas gerais de clientes e fornecedores da base de dados da Empresa Aços Pinhais - PR dos anos de 2008/2009, totalizando 61 clientes para 2008 e 2009 e para fornecedores 211 atores para o ano de 2008 e 212 para o ano de 2009.

$2^{\text {a }}$ ETAPA: Foi identificada a necessidade de fazer um corte na amostra, e o critério para seleção foram os 30 maiores clientes (com base no volume de vendas em $\mathrm{R} \$$ ) e os 30 maiores fornecedores (com base no volume de compras em $\mathrm{R} \$$ ).

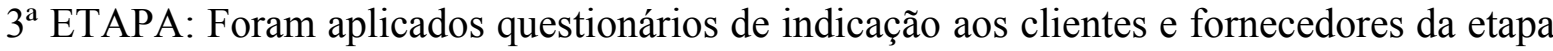
anterior. A aplicação do questionário ocorreu via e-mail e por contato telefônico.

$4^{\mathrm{a}}$ ETAPA: Com base nos dados da $3^{\mathrm{a}}$ etapa foram formatadas 4 matrizes (clientes 2008; clientes 2009; fornecedores 2008 e fornecedores 2009) e submetidas às análises do sistema UCINET.

\section{Apresentação e análise dos resultados}

No presente capítulo serão apresentados os dados da pesquisa e suas respectivas análises. Observe a seguir o contexto geral e específico.

\subsection{Fornecedores $2008-2009$}

Esta seção destina-se a apresentar uma análise temporal dos dados relativos aos fornecedores da empresa Aços Pinhais Ltda. Tendo coletados dados de trinta fornecedores selecionados com base no volume de fornecimento ( $R$ \$) em dois períodos (2008 e 2009), foi possível compará-los com a finalidade de entender melhor a evolução e tendência da rede e, a partir daí fazer algumas considerações com base em alguns dados estatísticos de grande relevância tais como, densidade, centralidade, distância e desvio padrão.

Para dar um melhor embasamento, a seguir é apresentado um quadro com a relação de fornecedores para cada período, a partir deste pode-se perceber a diferença em volume de fornecimento variante de um período para outro.

\begin{tabular}{|c|c|c|c|c|}
\hline \multicolumn{5}{|c|}{ Quadro 03 - Relação de fornecedores em 2008 e 2009} \\
\hline $\mathbf{N}^{\circ}$ & FORNECEDORES 2008 & $\begin{array}{c}\text { VOLUME DE } \\
\text { FORNECIMENTO } \\
(\mathrm{R} \$)\end{array}$ & FORNECEDORES 2009 & $\begin{array}{c}\text { VOLUME DE } \\
\text { FORNECIMENTO } \\
(\mathrm{R} \$)\end{array}$ \\
\hline 01 & Marcegaglia do Brasil Ltda & $\mathrm{R} \$ 3.134 .566,85$ & $\begin{array}{l}\text { Frefer Metal Plus Ind. e } \\
\text { Com. de Metais Ltda }\end{array}$ & $\mathrm{R} \$ 1.140 .258,24$ \\
\hline 02 & $\begin{array}{l}\text { Arcelormittal Brasil S/A } \\
\text { Siderúrgica }\end{array}$ & $\mathrm{R} \$ 1.413 .406,46$ & $\begin{array}{l}\text { Marcegaglia do Brasil } \\
\text { Ltda }\end{array}$ & $\mathrm{R} \$ 943.111,32$ \\
\hline 03 & $\begin{array}{l}\text { Gerdau Comercial de Aços } \\
\text { S/A }\end{array}$ & $\mathrm{R} \$ 954.386,68$ & Arcelormittal Brasil S/A & $\mathrm{R} \$ 588.035,12$ \\
\hline 04 & Benafer Com. e Ind. S/A & $\mathrm{R} \$ 878.749,94$ & Benafer Com. e Ind. S/A & $\mathrm{R} \$ 574.719,54$ \\
\hline 05 & Ciafal Com. e Ind. de & $\mathrm{R} \$ 500.312,20$ & Arcelormittal Distribuição & $\mathrm{R} \$ 545.645,47$ \\
\hline
\end{tabular}




\begin{tabular}{|c|c|c|c|c|}
\hline & $\begin{array}{l}\text { Artefatos de Ferro e Aço } \\
\text { Ltda }\end{array}$ & & Brasil S/A & \\
\hline 06 & $\begin{array}{l}\text { Cipalam Ind. e Comercio } \\
\text { de Laminados Ltda }\end{array}$ & $\mathrm{R} \$ 455.134,67$ & Gerdau Açominas S/A & $\mathrm{R} \$ 501.396,34$ \\
\hline 07 & $\begin{array}{l}\text { Frefer Metal Plus- Ind. e } \\
\text { Com. de Metais }\end{array}$ & $\mathrm{R} \$ 429.050,11$ & $\begin{array}{l}\text { Ciafal Com. e Ind. Art. } \\
\text { Ferro e Aço S/A }\end{array}$ & $\mathrm{R} \$ 476.609,75$ \\
\hline 08 & $\begin{array}{l}\text { Meincol Distribuidora de } \\
\text { Aços Ltda }\end{array}$ & $\mathrm{R} \$ 310.239,81$ & $\begin{array}{l}\text { Gerdau Comercial de } \\
\text { Aços S/A }\end{array}$ & $\mathrm{R} \$ 324.772,32$ \\
\hline 09 & Gerdau Açominas S/A & $\mathrm{R} \$ 286.073,19$ & Gasparini do Brasil & $\mathrm{R} \$ 315.839,44$ \\
\hline 10 & Arcelormittal Gonvarri & $\mathrm{R} \$ 235.313,38$ & $\begin{array}{l}\text { Cipalam Ind. e Com. de } \\
\text { Laminado }\end{array}$ & $\mathrm{R} \$ 303.899,66$ \\
\hline 11 & $\begin{array}{l}\text { Arcelormittal Distribuição } \\
\text { Brasil S/A }\end{array}$ & $\mathrm{R} \$ 178.823,63$ & $\begin{array}{l}\text { Meincol Distribuidora de } \\
\text { Aços Ltda }\end{array}$ & $\mathrm{R} \$ 256.454,83$ \\
\hline 12 & $\begin{array}{l}\text { Sonaex S;A Ind. e Com de } \\
\text { Aço }\end{array}$ & $\mathrm{R} \$ 174.831,38$ & Tuper Comércio S/A & $\mathrm{R} \$ 242.720,99$ \\
\hline 13 & $\begin{array}{l}\text { Schioppa Rodas e Rodízios } \\
\text { do Brasil }\end{array}$ & $\mathrm{R} \$ 136.680,65$ & Arcelormittal Gonvarri & $\mathrm{R} \$ 242.000,00$ \\
\hline 14 & $\begin{array}{l}\text { Jati Serviços Com. Imp. de } \\
\text { Aços Ltda }\end{array}$ & $\mathrm{R} \$ 125.327,45$ & Fercoi S/A & $\mathrm{R} \$ 210.334,62$ \\
\hline 15 & Fercoi S/A & $\mathrm{R} \$ 110.386,58$ & $\begin{array}{l}\text { Sonaex S/A Ind. e Com. } \\
\text { de Aço }\end{array}$ & $\mathrm{R} \$ 206.985,63$ \\
\hline 16 & $\begin{array}{l}\text { Multiaços Ind. e Com. de } \\
\text { Produtos Técnicos Ltda }\end{array}$ & $\mathrm{R} \$ 106.001,23$ & Sampaio Ferro e Aço Ltda & $\mathrm{R} \$ 159.950,67$ \\
\hline 17 & Osten Ferragens Ltda & $\mathrm{R} \$ 98.532,19$ & $\begin{array}{l}\text { Acos Favorit Distribuidora } \\
\text { Ltda -Curitiba }\end{array}$ & $\mathrm{R} \$ 155.440,17$ \\
\hline 18 & $\begin{array}{l}\text { Migsolda Com. e Manut. } \\
\text { de Produtos de Solda Ltda }\end{array}$ & $\mathrm{R} \$ 85.346,33$ & $\begin{array}{l}\text { Jati Serviços Com. Imp. } \\
\text { de Aços Ltda }\end{array}$ & $\mathrm{R} \$ 113.695,75$ \\
\hline 19 & $\begin{array}{l}\text { Ads Comércio de Materiais } \\
\text { Elétricos Ltda }\end{array}$ & $\mathrm{R} \$ 82.954,72$ & $\begin{array}{l}\text { Panatlântica Catarinense } \\
\text { S/A }\end{array}$ & $\mathrm{R} \$ 105.813,53$ \\
\hline 20 & Dova S/A & $\mathrm{R} \$ 77.188,71$ & Osten Ferragens Ltda & $\mathrm{R} \$ 92.452,14$ \\
\hline 21 & Tuper S/A & $\mathrm{R} \$ 72.608,93$ & $\begin{array}{l}\text { Randall Ind. e Com. de } \\
\text { Tintas Ltda. }\end{array}$ & $\mathrm{R} \$ 92.254,37$ \\
\hline 22 & $\begin{array}{l}\text { Randall Ind. e Com. de } \\
\text { Tintas Ltda. }\end{array}$ & $\mathrm{R} \$ 56.609,36$ & Dova S/A & $\mathrm{R} \$ 74.247,46$ \\
\hline 23 & Sampaio Ferro e Aço Ltda & $\mathrm{R} \$ 41.902,18$ & $\begin{array}{l}\text { Distribuidora de Tintas } \\
\text { Darka Ltda }\end{array}$ & $\mathrm{R} \$ 72.534,03$ \\
\hline 24 & $\begin{array}{l}\text { Vza Com. de Ferragens } \\
\text { Ltda }\end{array}$ & $\mathrm{R} \$ 37.572,39$ & $\begin{array}{l}\text { Schioppa Rodas e } \\
\text { Rodízios do Brasil }\end{array}$ & $\mathrm{R} \$ 68.072,62$ \\
\hline 25 & $\begin{array}{l}\text { Panatlântica Catarinense } \\
\text { S/A }\end{array}$ & $\mathrm{R} \$ 36.495,95$ & $\begin{array}{l}\text { Ads Comércio de } \\
\text { Materiais Elétricos Ltda }\end{array}$ & $\mathrm{R} \$ 66.622,50$ \\
\hline 26 & $\begin{array}{l}\text { Aços Favorit Distribuidora } \\
\text { Ltda }\end{array}$ & $\mathrm{R} \$ 29.503,43$ & $\begin{array}{l}\text { Vza Com. de Ferragens } \\
\text { Ltda }\end{array}$ & $\mathrm{R} \$ 58.850,14$ \\
\hline 27 & $\begin{array}{l}\text { Distribuidora de Tintas } \\
\text { Darka Ltda }\end{array}$ & $\mathrm{R} \$ 29.493,22$ & $\begin{array}{l}\text { Migsolda Com. e Manut. } \\
\text { de Produtos de Solda Ltda }\end{array}$ & $\mathrm{R} \$ 58.784,00$ \\
\hline 28 & $\begin{array}{l}\text { Açokorte Ind. Metalúrgica } \\
\text { e Com. Ltda }\end{array}$ & $\mathrm{R} \$ 27.391,50$ & $\begin{array}{l}\text { Oximig do Sul Comercial } \\
\text { Ltda }\end{array}$ & $\mathrm{R} \$ 55.536,82$ \\
\hline 29 & $\begin{array}{l}\text { Oximig do Sul Comercial } \\
\text { Ltda }\end{array}$ & $\mathrm{R} \$ 27.170,06$ & $\begin{array}{l}\text { Açokorte Ind. Metalúrgica } \\
\text { e Com. Ltda }\end{array}$ & $\mathrm{R} \$ 48.499,29$ \\
\hline 30 & Gasparini do Brasil & $\mathrm{R} \$ 25.999,88$ & $\begin{array}{l}\text { Multiaços Ind. Com. de } \\
\text { Produtos Técnicos Ltda }\end{array}$ & $\mathrm{R} \$ 38.888,01$ \\
\hline
\end{tabular}

Fonte: Autoria própria (2010)

O quadro 03 demonstra que houve em geral uma retração nos valores comercializados, isso é demonstrado pela queda nos volumes, havendo uma grande mudança no cenário empresarial, onde algumas empresas tiveram reduções drásticas e outras elevaram seu volume de fornecimento em grande escala, enquanto outras ainda se mantiveram no mesmo volume. Neste contexto, pode-se destacar a empresa MARCEGAGLIA DO BRASIL LTDA que, em 2008 tinha um volume de 
fornecimento de $\mathrm{R} \$ 3.134 .566,85$ e, em 2009 esse valor se reduziu para $\mathrm{R} \$ 943.111,32$ embora ela tenha se mantido entre as maiores empresas de fornecimento alterando sua posição de $1^{\circ}$ para $2^{\circ}$ lugar respectivamente. Também se destaca a empresa FREFER METAL PLUS- IND. E COM. DE METAIS que, em 2008 tinha um volume de fornecimento baseado em R\$ 429.050,11 e, em 2009 esse valor subiu para $\mathrm{R} \$ 1.140 .258,24$, nesse caso subindo de $7^{\circ}$ para $1^{\circ}$ lugar na relação de maiores fornecedores. Outro caso radical é o da empresa GASPARINI DO BRASIL, que em 2008 possuía um volume de fornecimento relativamente baixo (R\$25.999,88) e em 2009 por questões mercadológicas teve um aumento considerável passando para $\mathrm{R} \$ 315.839,44$. A partir do quadro 03 também podem ser visualizadas empresas que se mantiveram aproximadamente no mesmo nível de fornecimento como é o caso, por exemplo, da DOVA S/A e da OSTEN FERRAGENS LTDA.

O contexto da rede pode ser melhor visualizado a seguir, por meio de sociogramas gerais de cada período estudado (2008 e 2009).

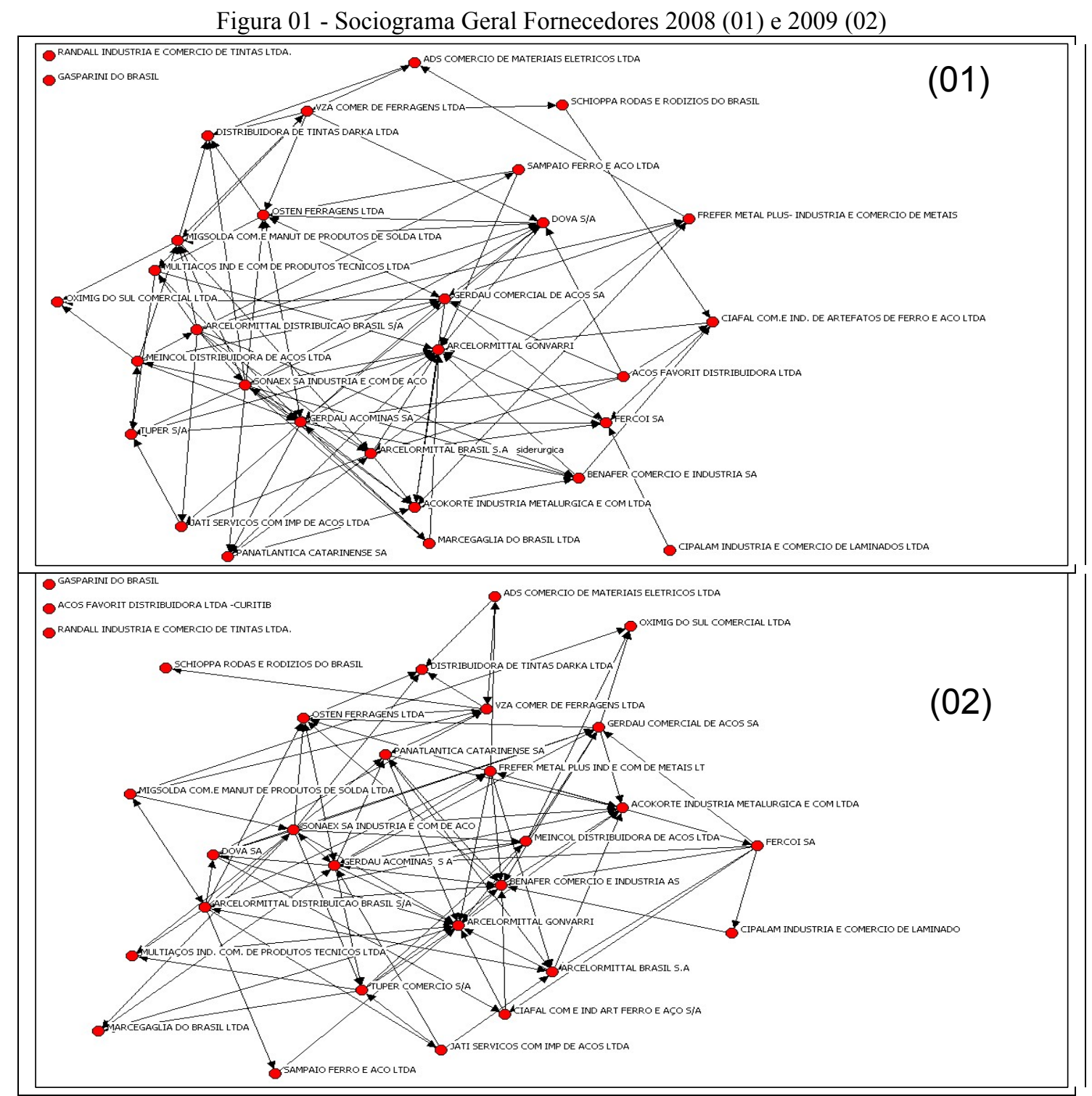

Fonte: Autoria própria (2010) 
Conforme evidenciado na figura 01, em 2008 havia duas empresas sem relacionamento com as demais (RANDALL IND. E COM. DE TINTAS LTDA e GASPARINI DO BRASIL), em 2009, este número aumentou para três empresas (RANDALL IND. E COM. DE TINTAS LTDA, AÇOS FAVORIT DISTRIBUIDORA LTDA-CURITIBA e GASPARINI DO BRASIL). Aqui se pode salientar que a empresa AÇOS FAVORIT DISTRIBUIDORA LTDA-CURITIBA, em 2008 se relacionava com empresas de elevado grau de centralidade (vide quadro 04) e em 2009 ela aparece sem vínculo algum, passando a fazer parte do grupo de empresas com centralidade igual a 0,00 .

Por meio da comparação entre valor de fornecimento e grau de centralidade considerando os dois períodos (2008 e 2009) pode-se ter uma abordagem mais explicada, para tanto, a seguir são apresentados os dez primeiros atores em ordem de grau de centralidade.

Quadro 04- Comparativo de centralidade por ator em 2008 e 2009

\begin{tabular}{|l|l|c|l|c|}
\hline $\mathbf{N}^{\circ}$ & \multicolumn{1}{|c|}{ Fornecedores 2008 } & $\begin{array}{c}\text { Grau de } \\
\text { centralidad } \\
\mathbf{e}\end{array}$ & \multicolumn{1}{|c|}{ Fornecedores 2009 } & $\begin{array}{c}\text { Grau de } \\
\text { centralidade }\end{array}$ \\
\hline $\mathbf{0 1}$ & Gerdau Açominas S/A & 0,079 & Sonaex S/A Ind. e Com. de Aço & 0,076 \\
\hline $\mathbf{0 2}$ & Sonaex S/A Ind. e Com.de Aço & 0,079 & Gerdau Açominas S/A & 0,076 \\
\hline $\mathbf{0 3}$ & Arcelormittal Gonvarri & 0,068 & Arcelormittal & 0,076 \\
\hline $\mathbf{0 4}$ & $\begin{array}{l}\text { Arcelormittal Distribuição Brasil } \\
\text { S/A }\end{array}$ & 0,058 & Benafer Com. e Ind. S/A & 0,065 \\
\hline $\mathbf{0 5}$ & Gerdau Comercial de Aços S/A & 0,053 & Arcelormittal Distribuição Brasil S/A & 0,060 \\
\hline $\mathbf{0 6}$ & $\begin{array}{l}\text { Arcelormittal Brasil S/A } \\
\text { Siderúrgica }\end{array}$ & 0,053 & Frefer Metal Plus Ind. e Com. de & 0,049 \\
\hline $\mathbf{0 7}$ & Dova S/A & 0,047 & Gerdais Ltda & 0,049 \\
\hline $\mathbf{0 8}$ & $\begin{array}{l}\text { Migsolda Com. e Manut. de } \\
\text { Produtos de Solda Ltda }\end{array}$ & 0,042 & Osten Ferragens Ltda & 0,043 \\
\hline $\mathbf{0 9}$ & Osten Ferragens Ltda & 0,042 & Tuper Comércio S/A & 0,043 \\
\hline $\mathbf{1 0}$ & $\begin{array}{l}\text { Açokorte Ind. Metalúrgica e Com. } \\
\text { Ltda }\end{array}$ & 0,042 & $\begin{array}{l}\text { Açokorte Ind. Metalúrgica e Com. } \\
\text { Ltda }\end{array}$ & 0,043 \\
\hline
\end{tabular}

Fonte: Autoria própria (2010)

Conforme pode ser observado no quadro 04, as três empresas com maior grau relacional permanecem as mesmas nos dois períodos, sendo elas: GERDAU AÇOMINAS S/A, SONAEX S/A IND. E COM. DE AÇO e ARCELORMITTAL GONVARRI, isso denota que elas continuam abrangendo uma fatia relativa de mercado e continuam com alta participação no relacionamento entre os atores da rede. Pode-se perceber que houve pouca variação no grau de centralidade de cada empresa, ou seja, a maioria delas se manteve relativamente no mesmo nível de 2008 para 2009 com pouca oscilação, ressaltando a empresa BENAFER COM. E IND. S/A, que em 2008 não se apresentava entre as 10 primeiras em grau de centralidade e em 2009 aparece em $4^{\text {a }}$ colocação com 0,065, ou seja se relacionando com 6,5\% dos atores da rede, assim como é o caso da FREFER METAL PLUS IND. E COM. DE METAIS LTDA e a TUPER COMÉRCIO S/A, que aparecem na $6^{\mathrm{a}}$ e $9^{\mathrm{a}}$ colocação respectivamente. Pode-se também observar que as empresas ARCELORMITTAL BRASIL S/A SIDERÚRGICA, DOVA S/A e MIGSOLDA COM. E MANUT. DE PRODUTOS DE SOLDA LTDA que em 2008 se apresentavam entre as dez empresas com maior grau de 
centralidade e em 2009 deixaram de aparecer, ou seja, deixaram de se relacionar com alguns atores devido à questões mercadológicas dando lugar a outras citadas acima e apresentadas no quadro 04 .

Analisando outros dados estatísticos de grande relevância como densidade geral, desvio padrão e distância média geral da rede, pode-se ter uma melhor visão da evolução e tendência da rede. A seguir é apresentado um quadro comparativo de dados estatísticos dos períodos de 2008 e 2009.

Quadro 05 - Comparativo de dados estatísticos em 2008 e 2009
\begin{tabular}{|l|c|c|}
\hline Indicador & $\mathbf{2 0 0 8}$ & $\mathbf{2 0 0 9}$ \\
\hline Densidade Geral & 0,1178 & 0,1167 \\
\hline Desvio Padrão & 0,3223 & 0,3210 \\
\hline Distância Média Geral da Rede & 3,296 & 2,881 \\
\hline
\end{tabular}

Fonte: Autoria própria (2010)

Conforme observado no quadro 05, pode-se perceber um grau de densidade figurado em 0,1178 para o ano de 2008 e 0,1167 para 2009 isso demonstra que praticamente $12 \%$ dos atores da rede se relacionam entre si, sendo todos fornecedores da empresa AÇOS PINHAIS LTDA. E com desvio padrão maior que a densidade média geral da rede, sugere que existe uma tendência de centralização dos nós em torno das maiores empresas. Também é possível observar no quadro 05 um grau de distância de 3,296 em 2008 e 2,881 em 2009 entre os atores, ou seja, para um ator localizar outro ator na rede se faz necessário contato em média com 3 atores nos dois períodos.

Por meio do quadro 05, é possível ainda destacar que, embora o volume de fornecimento (R\$) tenha se alterado relativamente, os dados da rede no geral, permaneceram com poucas alterações, o que demonstra estabilidade na rede nos períodos estudados, ressaltando que o volume de fornecimento $(\mathrm{R} \$)$ não é necessariamente ponto determinante para identificar a tendência da rede.

\subsection{Clientes $2008-2009$}

Seguindo o mesmo raciocínio da abordagem comparativa entre fornecedores da empresa Aços Pinhais Ltda, aqui é apresentada uma análise comparativa dos clientes desta mesma empresa nos respectivos anos de 2008 e 2009, neste contexto, a seguir é exposto um quadro com a relação de clientes de cada ano, para que a partir deste se possa realizar uma comparação, observando assim a evolução da rede.

Quadro 06 - Relação de clientes em 2008 e 2009

\begin{tabular}{|c|l|r|l|r|}
\hline$N^{\circ}$ & \multicolumn{1}{|c|}{ CLIENTES 2008 } & $\begin{array}{c}\text { VOLUME DE } \\
\text { COMPRA (R\$) }\end{array}$ & \multicolumn{1}{c|}{ CLIENTES 2009 } & \multicolumn{1}{c|}{$\begin{array}{c}\text { VOLUME DE } \\
\text { COMPRA (R\$) }\end{array}$} \\
\hline 01 & Cassol Pré-Fabricados Ltda & $\mathrm{R} \$ 637.838,43$ & $\begin{array}{l}\text { Stockfer Com. Dist.de Ferro } \\
\text { Aço Ltda }\end{array}$ & $\mathrm{R} \$ 293.431,71$ \\
\hline 02 & Gsn System do Brasil Ltda & $\mathrm{R} \$ 459.266,42$ & Gsn System do Brasil Ltda & $\mathrm{R} \$ 277.087,00$ \\
\hline 03 & $\begin{array}{l}\text { Eaa Equipamentos } \\
\text { Automotivos Araucária Ltda }\end{array}$ & $\mathrm{R} \$ 452.619,59$ & $\begin{array}{l}\text { Rodavelle Ind. de } \\
\text { Equipamentos Ltda }\end{array}$ & $\mathrm{R} \$ 267.248,77$ \\
\hline
\end{tabular}




\begin{tabular}{|c|c|c|c|c|}
\hline 04 & $\begin{array}{l}\text { Stockfer Com. Dist. de Ferro } \\
\text { Aço Ltda }\end{array}$ & $\mathrm{R} \$ 341.531,87$ & $\begin{array}{l}\text { Eaa Equipamentos } \\
\text { Automotivos Araucária Ltda }\end{array}$ & $\mathrm{R} \$ 177.436,21$ \\
\hline 05 & $\begin{array}{l}\text { Montinil Montagens e } \\
\text { Manutenção Industrial }\end{array}$ & $\mathrm{R} \$ 287.441,13$ & $\begin{array}{l}\text { Damaeq Davilla Ind. Mec. De } \\
\text { Máquinas Ltda }\end{array}$ & $\mathrm{R} \$ 135.700,56$ \\
\hline 06 & $\begin{array}{l}\text { Damaeq Davilla Ind. Mec. de } \\
\text { Máquinas Ltda }\end{array}$ & $\mathrm{R} \$ 226.460,26$ & Renault do Brasil S/A & $\mathrm{R} \$ 127.317,02$ \\
\hline 07 & Artmáquinas Ltda & $\mathrm{R} \$ 221.130,96$ & Eurotech do Brasil Ltda & $\mathrm{R} \$ 123.755,00$ \\
\hline 08 & $\begin{array}{l}\text { Metálica Estruturas de Aço } \\
\text { Ltda }\end{array}$ & $\mathrm{R} \$ 149.924,52$ & Aços Urânio Comercial Ltda & $\mathrm{R} \$ 118.693,75$ \\
\hline 09 & Eurotech do Brasil Ltda & $\mathrm{R} \$ 140.912,00$ & Artmáquinas Ltda & $\mathrm{R} \$ 106.004,45$ \\
\hline 10 & $\begin{array}{l}\text { Rodavelle Ind. de } \\
\text { Equipamentos Ltda }\end{array}$ & $\mathrm{R} \$ 103.334,00$ & $\begin{array}{l}\text { Vetor Engenharia e Tecnologia } \\
\text { Ltda }\end{array}$ & $\mathrm{R} \$ 94.633,39$ \\
\hline 11 & Renault do Brasil S/A & $\mathrm{R} \$ 81.962,30$ & Cassol Pré-Fabricados Ltda & $\mathrm{R} \$ 92.862,00$ \\
\hline 12 & Metal Cairo Ltda & $\mathrm{R} \$ 80.578,93$ & $\begin{array}{l}\text { Montinil Montagens e } \\
\text { Manutenção Industrial }\end{array}$ & $\mathrm{R} \$ 86.637,46$ \\
\hline 13 & Aços Urânio Comercial Ltda & $\mathrm{R} \$ 79.217,14$ & $\begin{array}{l}\text { Inovadoor Portões } \\
\text { Automáticos Ltda }\end{array}$ & $\mathrm{R} \$ 86.249,00$ \\
\hline 14 & $\begin{array}{l}\text { Aços Continente Ind. e Com. } \\
\text { Ltda }\end{array}$ & $\mathrm{R} \$ 77.367,00$ & $\begin{array}{l}\text { Metálica Estruturas de Aço } \\
\text { Ltda }\end{array}$ & $\mathrm{R} \$ 83.635,00$ \\
\hline 15 & $\begin{array}{l}\text { Ditual Dist. de Ferro e Aços } \\
\text { Ltda }\end{array}$ & $\mathrm{R} \$ 74.518,00$ & $\begin{array}{l}\text { Aços Continente Ind. e Com. } \\
\text { Ltda }\end{array}$ & $\mathrm{R} \$ 81.305,19$ \\
\hline 16 & $\begin{array}{l}\text { Mvc Componentes Plásticos } \\
\text { Ltda }\end{array}$ & $\mathrm{R} \$ 68.527,00$ & $\begin{array}{l}\text { Mvc Componentes Plásticos } \\
\text { Ltda }\end{array}$ & $\mathrm{R} \$ 70.600,23$ \\
\hline 17 & Metalúrgica Matrix Ltda & $\mathrm{R} \$ 62.617,70$ & Metal Cairo Ltda & $\mathrm{R} \$ 60.869,00$ \\
\hline 18 & $\begin{array}{l}\text { Truck Center Equipamentos } \\
\text { Automotivos Ltda }\end{array}$ & $R \$ 55.334,00$ & Gestamp Paraná S/A & $\mathrm{R} \$ 60.029,72$ \\
\hline 19 & $\begin{array}{l}\text { Zintec Zincagens Técnicas } \\
\text { Ltda }\end{array}$ & $\mathrm{R} \$ 50.953,17$ & $\begin{array}{l}\text { Co Mueller Com. de Motores e } \\
\text { Bombas Ltda }\end{array}$ & $\mathrm{R} \$ 55.190,64$ \\
\hline 20 & Gasparini do Brasil S/A & $\mathrm{R} \$ 50.212,12$ & $\begin{array}{l}\text { Ditual Dist. de Ferro e Aços } \\
\text { Ltda }\end{array}$ & $\mathrm{R} \$ 49.321,34$ \\
\hline 21 & Gestamp Paraná S/A & $\mathrm{R} \$ 50.194,70$ & Metalúrgica Matrix Ltda & $\mathrm{R} \$ 42.003,00$ \\
\hline 22 & $\begin{array}{l}\text { Inovadoor Portões } \\
\text { Automáticos Ltda }\end{array}$ & $\mathrm{R} \$ 44.805,00$ & $\begin{array}{l}\text { Zintec Zincagens Técnicas } \\
\text { Ltda }\end{array}$ & $\mathrm{R} \$ 41.825,00$ \\
\hline 23 & $\begin{array}{l}\text { Fortaleza Tratores Com. de } \\
\text { Peças de Serviços Ltda }\end{array}$ & $\mathrm{R} \$ 39.184,00$ & $\begin{array}{l}\text { Greif Embalagens Ind. do } \\
\text { Brasil Ltda }\end{array}$ & $\mathrm{R} \$ 40.564,97$ \\
\hline 24 & $\begin{array}{l}\text { Greif Embalagens Industriais } \\
\text { do Brasil Ltda }\end{array}$ & $\mathrm{R} \$ 36.310,00$ & Gasparini do Brasil S/A & $\mathrm{R} \$ 21.717,00$ \\
\hline 25 & Lança Equipamentos Ltda & $\mathrm{R} \$ 28.563,99$ & $\begin{array}{l}\text { Fortaleza Tratores Com de } \\
\text { Peças de Serviços Ltda }\end{array}$ & $\mathrm{R} \$ 20.455,00$ \\
\hline 26 & Germer Porcelanas Finas S/A & $\mathrm{R} \$ 27.294,00$ & $\begin{array}{l}\text { Truck Center Equipamentos } \\
\text { Automotivos Ltda }\end{array}$ & $\mathrm{R} \$ 20.359,00$ \\
\hline 27 & $\begin{array}{l}\text { Co Mueller Com. de Motores } \\
\text { e Bombas Ltda }\end{array}$ & $\mathrm{R} \$ 26.474,00$ & $\begin{array}{l}\text { Comau do Brasil Ind. e Com. } \\
\text { Ltda }\end{array}$ & $\mathrm{R} \$ 17.743,29$ \\
\hline 28 & $\begin{array}{l}\text { Vetor Engenharia e } \\
\text { Tecnologia Ltda }\end{array}$ & $\mathrm{R} \$ 24.473,00$ & Gonvarri Brasil S/A & $\mathrm{R} \$ 17.568,52$ \\
\hline 29 & Gonvarri Brasil S/A & $\mathrm{R} \$ 22.692,00$ & Germer Porcelanas Finas S/A & $\mathrm{R} \$ 16.557,00$ \\
\hline 30 & $\begin{array}{l}\text { Comau do Brasil Ind. e Com. } \\
\text { Ltda }\end{array}$ & $\mathrm{R} \$ 22.058,00$ & Lança Equipamentos Ltda & $\mathrm{R} \$ 16.159,66$ \\
\hline
\end{tabular}

Fonte: Autoria própria (2010)

As informações constantes no quadro 06 demonstram que, assim como o volume de fornecimento da empresa Aços Pinhais Ltda, o volume de compras também sofreu redução. Uma situação a ser analisada é a das empresas CASSOL PRÉ-FABRICADOS LTDA e MONTINIL MONTAGENS E MANUTENÇÃO INDUSTRIAL, que passaram de $1^{\circ}$ e $5^{\circ}$ lugares respectivamente para $11^{\circ}$ e $12^{\circ}$ lugares (vide quadro 06), tendo seus valores de compra reduzidos, no caso da CASSOL PRE FABRICADOS LTDA de R\$ 637.838,43 para R\$ 92.862,00 e no caso da 
MONTINIL MONTAGENS E MANUTENÇÃO INDUSTRIAL de R\$ 287.441,13 para R\$ 86.637,46. Outro caso a ser salientado é o da empresa STOCKFER COM. DIST. DE FERRO AÇO LTDA, que apesar de ter reduzido seu volume de compras de $\mathrm{R} \$ 341.531,87$ para $\mathrm{R} \$ 293.431,71$ permaneceu entre os principais clientes da empresa Aços Pinhais Ltda, subindo de $4^{\mathrm{a}}$ para $1^{\mathrm{a}}$ colocação na lista de maiores clientes de 2008 para 2009.

Para que se possa melhor visualizar o contexto da rede, a seguir são apresentados os sociogramas gerais de cada período estudado (2008 e 2009).

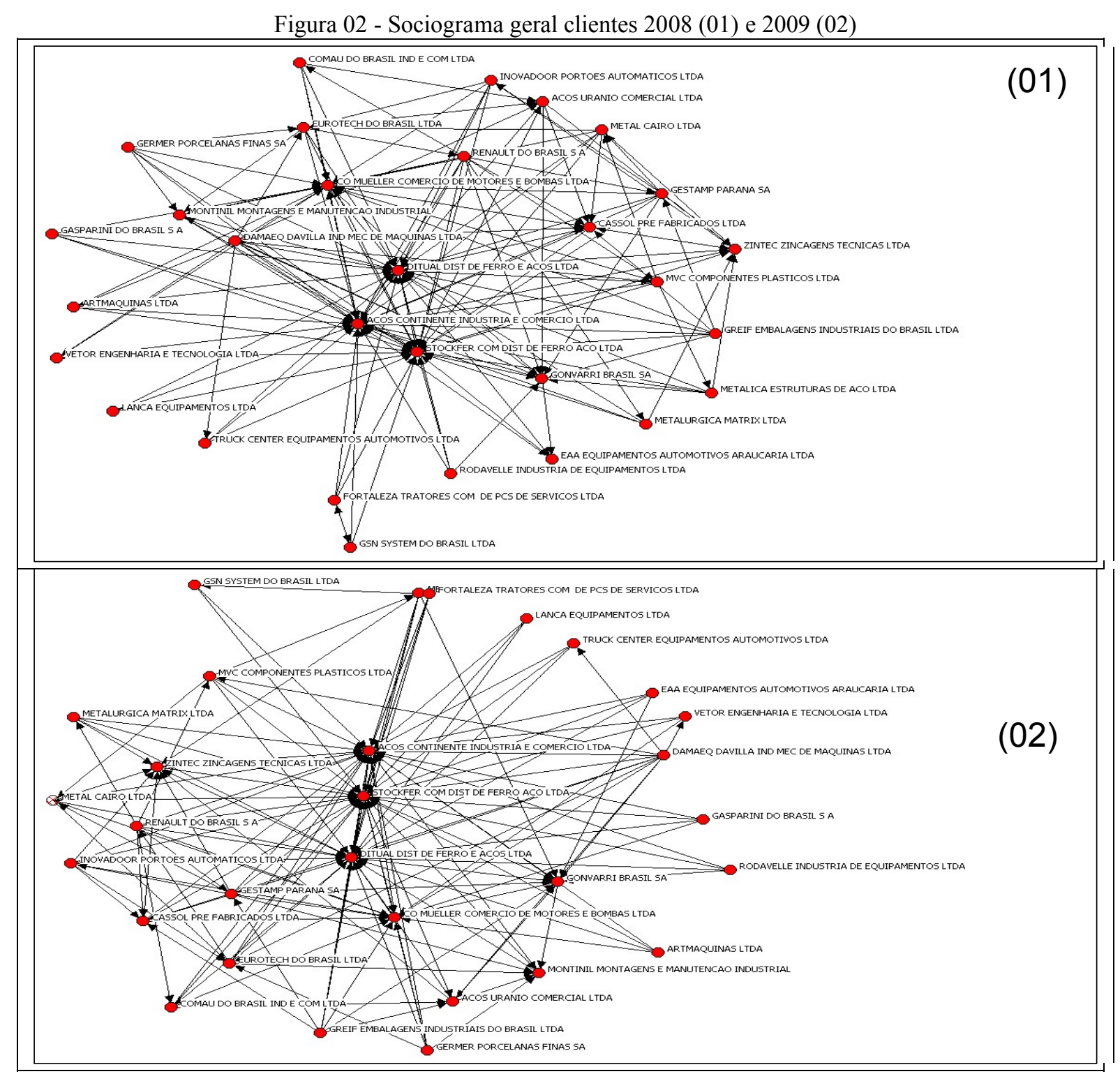

Fonte: Autoria própria (2010)

Conforme se pode observar na figura 02, em 2008 a rede se concentrava em basicamente 3 empresas: STOCKFER COM. DIST. DE FERRO AÇO LTDA, AÇOS CONTINENTE IND. E COM. LTDA e DITUAL DIST. DE FERRO E AÇOS LTDA, cenário este que não mudou para o ano de 2009 embora o volume de compras destas empresas tenha se reduzido, ou seja, a redução 
não afetou seu grau de relacionamentos, isso pode ser melhor observado no quadro comparativo de centralidade por ator demonstrado a seguir.

Quadro 07 - Comparativo de centralidade por ator em 2008 e 2009

\begin{tabular}{|c|c|c|c|c|}
\hline $\mathbf{N}^{\circ}$ & Clientes 2008 & $\begin{array}{c}\text { Grau de } \\
\text { centralidade }\end{array}$ & Clientes 2009 & $\begin{array}{c}\text { Grau de } \\
\text { centralidade }\end{array}$ \\
\hline 01 & $\begin{array}{l}\text { Stockfer Com. Dist. de Ferro } \\
\text { Aço Ltda }\end{array}$ & 0,099 & $\begin{array}{l}\text { Stockfer Com. Dist. de Ferro Aço } \\
\text { Ltda }\end{array}$ & 0,105 \\
\hline 02 & $\begin{array}{l}\text { Aços Continente Ind. e Com. } \\
\text { Ltda }\end{array}$ & 0,099 & Aços Continente Ind. e Com. Ltda & 0,101 \\
\hline 03 & $\begin{array}{l}\text { Ditual Dist. de Ferro e Aços } \\
\text { Ltda }\end{array}$ & 0,096 & Ditual Dist. de Ferro e Aços Ltda & 0,098 \\
\hline 04 & $\begin{array}{l}\text { Co Mueller Com. de Motores } \\
\text { e Bombas Ltda }\end{array}$ & 0,064 & $\begin{array}{l}\text { Co Mueller Com. de Motores e } \\
\text { Bombas Ltda }\end{array}$ & 0,058 \\
\hline 05 & Gonvarri Brasil S/A & 0,046 & Gonvarri Brasil S/A & 0,043 \\
\hline 06 & $\begin{array}{l}\text { Damaeq Davilla Ind. Mec. de } \\
\text { Máquinas Ltda }\end{array}$ & 0,043 & Gestamp Paraná S/A & 0,040 \\
\hline 07 & Renault do Brasil S/A & 0,043 & $\begin{array}{l}\text { Damaeq Davilla Ind. Mec. de } \\
\text { Máquinas Ltda }\end{array}$ & 0,040 \\
\hline 08 & $\begin{array}{l}\text { Zintec Zincagens Técnicas } \\
\text { Ltda }\end{array}$ & 0,035 & Renault do Brasil S/A & 0,036 \\
\hline 09 & Cassol Pré-Fabricados Ltda & 0,035 & Zintec Zincagens Técnicas Ltda & 0,036 \\
\hline 10 & Eurotech do Brasil Ltda & 0,035 & Eurotech do Brasil Ltda & 0,033 \\
\hline
\end{tabular}

Fonte: Autoria própria (2010)

Conforme é observado no quadro 07 , as três empresas com maior grau de centralidade permanecem as mesmas nos dois períodos, sendo elas: STOCKFER COM. DIST. DE FERRO AÇO LTDA, AÇOS CONTINENTE IND. E COM. LTDA e DITUAL DIST. DE FERRO E AÇOS LTDA, isso denota que elas continuam abrangendo uma fatia relativa de mercado (considerando o mercado de estudo) e continuam com alta participação no relacionamento entre os atores da rede. Por meio do quadro 07 , pode-se perceber que assim como na comparação de fornecedores, aqui também houve pouca variação no grau de centralidade de cada empresa, assim sendo, a maioria delas se manteve no mesmo nível de 2008 para 2009, destacando a empresa GESTAMP PARANÁ S/A, que em 2008 não se apresentava entre as 10 primeiras em grau de centralidade e em 2009 aparece em $6^{\mathrm{a}}$ colocação com 0,040 , ou seja se relacionando com $4 \%$ dos atores da rede. Também vale considerar a empresa CASSOL PRÉ-FABRICADOS LTDA que em 2008 se apresentava em $9^{\circ}$ lugar em grau de centralidade e em 2009 deixou de aparecer entre os dez primeiros, ou seja deixou de se relacionar com alguns atores devido à questões mercadológicas.

Comparando outros dados estatísticos de grande importância como densidade geral, desvio padrão e distância média geral da rede, pode-se ter uma melhor visão da evolução e tendência da rede, para tanto a seguir é apresentado um quadro comparativo de dados estatísticos dos períodos de 2008 e 2009.

Quadro 08 - Comparativo de dados estatísticos em 2008 e 2009

\begin{tabular}{|l|c|c|}
\hline Indicador & $\mathbf{2 0 0 8}$ & $\mathbf{2 0 0 9}$ \\
\hline Densidade Geral & 0,1759 & 0,1701 \\
\hline
\end{tabular}


Desvio Padrão Distância Média Geral da Rede

Fonte: Autoria própria (2010)

Conforme observado no quadro 08 , pode-se perceber um grau de densidade figurado em 0,1759 para o ano de 2008 e 0,1701 para 2009 isso demonstra que $17 \%$ dos atores da rede se relacionam entre si, sendo todos fornecedores da empresa AÇOS PINHAIS LTDA. E com desvio padrão maior que a densidade média geral da rede, sugere que existe uma tendência de centralização dos nós em torno das maiores empresas. Também é possível observar no quadro 08 um grau de distância de 1,822 em 2008 e 1,771 em 2009 entre os atores, ou seja, para um ator localizar outro ator na rede se faz necessário contato em média com 2 atores nos dois períodos.

Observando o quadro 08 acima, é possível salientar que, embora o volume de compras (R\$) tenha se alterado relativamente, os dados da rede no geral, permaneceram com poucas transformações, o que demonstra estabilidade na rede nos períodos estudados, ressaltando que o volume de compras (R\$) não é necessariamente ponto determinante para identificar a tendência da rede.

\subsection{Análise integrada do setor}

Analisando os dois lados (fornecedores e clientes), pode-se entender que a rede encontra-se de maneira estável, com pouca variação de um período para outro, isso se confirma nos dados estatísticos apresentados. Percebe-se que a densidade não varia muito em nenhum dos casos, bem como o desvio padrão e a distância média entre os atores da rede, isso significa que a rede não sofreu uma movimentação brusca de um período para o outro. Pode-se salientar que de 2008 para 2009, tanto fornecedores quanto clientes tiveram seus volumes financeiros relativamente reduzidos e nem por isso os dados descritos acima de modificaram, então pode-se perceber que o volume financeiro não é uma variante determinante para a análise de tendência da rede. Outra questão importante é que as principais empresas detentoras dos maiores graus de centralidade, ou seja, as de maior importância relacional para o mercado estudado permaneceram as mesmas nos dois períodos estudados, denotando a abrangência de uma importante fatia de mercado.

\section{Considerações finais}

A identificação e compreensão das relações entre atores nos mercados e suas respectivas participações financeiras, surgem como importante fator de análise e setores, nesse sentido, dentre as considerações finais apresentadas, destaca-se a participação relacional entre os membros da rede do setor metal-mecânico, como uma importante evidência de cooperação e competição num ambiente que de maneira implícita, apresenta determinado nível de controle. A interação na rede 
social potencializa as ações de compra e venda, visto que as organizações trabalham em torno de objetivos comuns que apresentam características de cooperação e competição de forma congruente.

Diante disso, o presente estudo evidenciou a participação e contribuição de cada ator envolvido no canal de distribuição do setor metal-mecânico da região de São José dos Pinhais, identificando sua evolução por meio de mapeamento de redes.

Embora o estudo de redes sociais, seja um assunto novo em base literal, é prática constante, porém, quase imperceptível nas relações entre as organizações. Indica-se neste sentido a necessidade de observar o setor sob os vários aspectos, para identificar ou criar as ferramentas que possam promover e fazer evoluir as relações e a estrutura da rede.

Finalmente, o estudo pode contribuir com a literatura sobre redes sociais, canal de distribuição e com o setor metal-mecânico a partir da análise dos dados e informações coletados. Esta contribuição permitiu a percepção da situação real do setor, em suas abordagens relacionais e de participação financeira, estabelecendo um exemplo da contribuição do mapeamento e análise de setores específicos por meio de análise de redes numa perspectiva temporal.

\begin{abstract}
Globalization encourages the need to increase competitiveness in the organizations, making the establishment of partnerships become essential. One of the emerging themes in organizational studies has been the concept of organizational networks. Facing the fierce competition faced by organizations today, the networks are emphasized as a viable alternative, representing a response on issues of competitiveness, business strategy and organizational structure. This research was conducted in a network of suppliers and customers of the metal-mechanic in the metropolitan region of Curitiba - PR. The study aimed to understand how this sector relates to and what are its main actors, showing its evolution over the period (2008/2009). As a result, we verified the existence of a system of interaction between actors in the distribution channel of the metal-mechanic sector, known as suppliers and customers in respect of the principal actors in relational structure in the network.
\end{abstract}

Keywords: social and organizational networks; analysis of networks; metal-mechanic.

\title{
Referências
}

ANDION, C. Análise de redes e desenvolvimento local sustentável. Revista de Administração Pública, v. 5, set./out. Rio de Janeiro, 2003.

AMATO NETO, J. Redes de cooperação produtiva e clusters regionais: oportunidades para pequenas e médias empresas. São Paulo: editora Atlas, 2000.

BURT, R. S. Structural holes: the social structure of competition. Massachusetts: Harvard University, 1992.

CASAROTTO, N. F.; PIRES, L. H. Redes de pequenas e médias empresas e desenvolvimento local: estratégias para a conquista da competitividade global com base na experiência italiana. São Paulo: Atlas, 2001.

CASTElls, M. A sociedade em rede. 6. ed., v. 1. São Paulo: editora Paz e Terra, 2002.

CRUZ, J. A. W. A união faz a força: a cooperação como estratégia de sobrevivência organizacional. Curitiba: editora Protexto, 2007. 
CRUZ, J. A. W.; MARTINS, T. S.; AUGUSTO, P. O. M. Redes sociais e organizacionais em administração. Curitiba: Juruá, 2008.

CRUZ FILHO, P. R. A.; OLIVEIRA, M. R. S. de. Governança e gestão de redes na esfera pública municipal: o caso da rede de proteção à criança e ao adolescente em situação de risco para a violência em Curitiba. $2006.150 \mathrm{f}$. Dissertação (Mestrado) - Pontifícia Universidade Católica do Paraná, Curitiba, 2006.

FISCHER, L. M.; SPINOSA, L. M. Promovendo inovação no setor de tic por meio de redes sociais. In: Redes sociais e organizacionais em administração. Curitiba: editora Juruá, 2008.

HUTT, M. D. et al. Case study defining the social network of a strategic alliance. Sloan Management Review, 2000.

LEMOS, I. S. Estratégias competitivo-cooperativas para o desenvolvimento regional sustentável via turismo: o caso de Treze Tílias - SC. Dissertação do Mestrado em Administração Estratégica. Curitiba: PUCPR, 2004.

LINS, H. N. Clusters industriais, competitividade e desenvolvimento regional: da experiência à necessidade de promoção. Estudos Econômicos, São Paulo, v. 30, n. 2, p. 233- 265, abr-jun. 2000.

MACHADO, S. C. L.; COSER, C. Isomorfismo mimético e lacunas estruturais em um campo organizacional. In: Redes sociais e organizacionais em administração. Curitiba: editora Juruá, 2008.

MARTES, A. C. B. et al. Redes e empresas: imersão social, estratégia e inovação organizacional. In: Redes sociais e organizacionais em administração. Curitiba: editora Juruá, 2008.

QUANT, C. O.; CRUZ, J. A. W.; LEMOS, I. S. Análise de redes de inovação em arranjos produtivos locais: o caso de APL em malharias de Imbituva - Pr. In: Redes sociais e organizacionais em administração. Curitiba: editora Juruá, 2008.

PORTER, M. E. Competição on competition: estratégias competitivas essenciais. Rio de Janeiro: editora Campus, 1999.

PORTER, M. E. Vantagem competitiva: criando e sustentando um desempenho superior. 13. ed. Rio de Janeiro: editora Campus, 1998.

POWELL, W. W. Neither market nor hierarchy: network forms of organization. Research in Organizational Behavior, v. 12, p. 295-336, 1990.

SHIRKY, C. Análise de redes - elogio à interdependência. HSM management, São Paulo, v. 3, n. 62, p.10, mai/jun. 2007.

SOUZA, Q. R. Governo de redes interorganizacionais no terceiro setor: níveis de controle formal em atividades operacionais de gestão do conhecimento - o caso do COEP Paraná 2000-2003. 2004. Dissertação (Mestrado em Administração) - Pontifícia Universidade Católica do Paraná, Curitiba, 2004.

ZACCARELLI, S. B. Estratégia e sucesso nas empresas. São Paulo: editora Saraiva, 2004.

\section{Dados dos autores}

Nome completo: Edinéia Aparecida Ivankio

Filiação institucional: Pontifícia Universidade Católica do Paraná

Departamento: Centro de Ciências Sociais Aplicadas

Função ou cargo ocupado: Discente

Endereço completo para correspondência (bairro, cidade, estado, país e CEP):

Av das Américas, 779 - Cidade Jardim - São José dos Pinhais - Paraná - Brasil 
CEP 83030-640

Telefones para contato: (41) 3382-1339 / 9198-5117

e-mail:edineiaivankio@bol.com.br

Nome completo: Fernando Claudino

Filiação institucional: Pontifícia Universidade Católica do Paraná

Departamento: Centro de Ciências Sociais Aplicadas

Função ou cargo ocupado: Discente

Endereço completo para correspondência (bairro, cidade, estado, país e CEP):

Rua Dr. Motta Junior, 1964 - Centro - São José dos Pinhais - Paraná - Brasil

CEP 83025-030

Telefones para contato: (41) 3282-4945 / 9185-4545

e-mail:fernando.claudino@hotmail.com

Nome completo: June Alisson Westarb Cruz

Filiação institucional: Pontifícia Universidade Católica do Paraná

Departamento: Centro de Ciências Sociais Aplicadas

Função ou cargo ocupado: Professor

Endereço completo para correspondência (bairro, cidade, estado, país e CEP):

Rua João Gava, 78 - São Lourenço - Curitiba - Paraná - Brasil

CEP 82130-010

Telefones para contato: (41) 9615-0089

e-mail: june.cruz@pucpr.br

Nome completo: Natália Machado Costa

Filiação institucional: Pontifícia Universidade Católica do Paraná

Departamento: Centro de Ciências Sociais Aplicadas

Função ou cargo ocupado: Discente 
Endereço completo para correspondência (bairro, cidade, estado, país e CEP):

Av. Rio Branco, caixa postal 1043 - Centro - São José dos Pinhais - Paraná - Brasil

CEP 83005-980

Telefones para contato: (41) 9167-8271 / 9940-1444 / 3382-9733

e-mail: natalia_tati2004@yahoo.com.br

Nome completo: Valdir Ribeiro da Silva

Filiação institucional: Pontifícia Universidade Católica do Paraná

Departamento: Centro de Ciências Sociais Aplicadas

Função ou cargo ocupado: Discente

Endereço completo para correspondência (bairro, cidade, estado, país e CEP):

Rua C, 28 Conjunto Açucena - Boqueirão - Curitiba - Paraná - Brasil

CEP $81750-500$

Telefones para contato: (41) 3286-5058 / 9668-2345

e-mail:valdir.silva@pr.senai.br

Nome completo: Vilma Fátima de Campos Bergamasco

Filiação institucional: Pontifícia Universidade Católica do Paraná

Departamento: Centro de Ciências Sociais Aplicadas

Função ou cargo ocupado: Discente

Endereço completo para correspondência (bairro, cidade, estado, país e CEP):

Rua Castro, 1073 - Jardim Cruzeiro - São José dos Pinhais - Paraná - Brasil

CEP 83010-080

Telefones para contato: (41) 3382-1455 / 9962-3315

e-mail:vilma@acospinhais.com.br

Enviado em: 17/06/2010

Aprovado em: 20/06/2011 